\title{
Os ritmos da memória: a lembrança e a reminiscência na escuta musical online
}

\author{
ROdRIGo Fonseca e Rodrigues \\ Doutor em Comunicação e Semiótica \\ Professor na Universidade Fumec - MG \\ rodfroes@gmail.com
}

\begin{abstract}
Resumo
Este texto trata de problematizar as modalidades da memória musical que trespassam os hábitos de freqüência à internet. Propõe-se a questionar as intersecções entre os processos mnemônicos em ocasiões de escuta online e as suas potencialidades para novos modos de sociabilidade musical. Trata-se, portanto, de saber como a experiência paradoxal da escuta - tanto como realidade de sensações quanto de práticas socializadas - pode-se diferenciar por meio de recursos de sítios-programas como os do YouTube, do SoulSeek ou do MySpace, entre muitos. Supondo que a experiência musical advenha de sínteses de múltiplas memórias, acredita-se que modalidades criativas de aproximação da música via internet podem impulsionar singularidades nas performances mnemônicas e nas práticas de socialização da escuta como 'micropolíticas'. Isto pode produzir uma resistência à orquestração das 'imagens' da memória musical pela cultura midiática.
\end{abstract}

Palavras-chave: escuta musical; memória; sociabilidade; internet.

\section{A memória como aporte metodológico na questão dos modos de sociabilidade ligados à escuta musical online}

$\mathrm{E}$ NGOLFADOS PELOS HÁBITOS CONTEMPORÂNEOS COM as mídias informáticas, particularmente com a internet, nem sempre nos damos conta de virtualidades que, mesmo imperceptível e involuntariamente, afetam muitos de nossos ritmos corporais, atuando na sua carne, em sua química, na sensibilidade, em sua aptidão linguística e imaginativa. Em momentos aos quais nos dedicamos à freqüentação da web não temos tempo de nos apercebermos o quanto as nossas habilidades mnemônicas são trespassadas sultimente por novos modos de trabalho. Especulações teóricas recentes se empenham para alcançar deduzir esses ritmos mnemônicos catalisados nos modos de contato com a internet, que nos afetam para aquém de toda a semiose e que, no entanto, nos movem e nos modificam sensivelmente.

E quando se trata da escuta musical, espreitam-se mudanças impingidas aos hábitos da memória a operarem para além das forças tecnológicas e dos recursos discursivos da mídia digital. De fato, fazem-se novas oportunidades de encontro com a música nas páginas da rede. Divulgam-se atualmente composições, projetos, grupos musicais, gêneros, canções, idéias, sonoridades etc. E o que mais nos importa sa- 
lientar aqui, promovem-se ocasiões para renovarmos a sensibilidade ligada à escuta musical.

Algumas das modalidades de iniciativas experimentais têm nascido da freqüentação criativa das arquiteturas algorítmicas, como a do YouTube, sítio que nos permite assistir a uma infinitude de arquivos audiovisuais depositados pelos próprios freqüentadores. Também são dignos de atenção o SoulSeek, sítio-programa $p 2 p$ (person-to-person) que possibilita trocas de arquivos raros de música, de vídeo-clipes, de filmes e de literatura entre membros que respeitam regras relacionadas a uma política inovadora de socialização da música; e o MySpace, sítio hospedeiro de compositores, organizado e criterioso, que funciona como um portal qualificado para divulgação e apreciação de trabalhos musicais e audiovisuais, entre outras atividades criadoras. Se o nosso ponto de partida conceitual se ancorasse nas operações da memória como representação e valoração de um passado histórico, um estudo das possibilidades destes sítios para um processo recuperação da memória coletiva já seria válido. É surpreendente a sua capacidade de arquivamento e de acessibilidade dos registros depositados e compartilhados pelos seus freqüentadores.

Como um investimento de caráter metodológico diferente, contudo, este breve texto visa a especular acerca de outras potencialidades da memória, de experimentações singulares tais como a anamnese e a reminiscência, valendo-se da prática da escuta musical na internet. Começa-se pelo esboço de algumas questões iniciais, primeiramente, de espectro mais geral. Pergunta-se: como se processam os ritmos da memória quando implicada à prática social da escuta musical? Como se operam as memórias implicadas na escuta? E quais as prerrogativas da máquina da comunicação midiática sobre a memória na escuta? E os axiomas da cultura, da sociabilidade, da 'razão comunicacional' podem mesmo dizer algo da real potencialidade da música?

O nosso problema principal deverá se desdobrar de ora em diante: haveria possibilidades de afirmação de uma sociabilidade apoiada num ethos da memória ligado à escuta? Transpondo estas questões para o âmbito das redes informáticas, em que aspectos a internet poderia potencializar a circunstância criativa da memória nos modos de escuta musical on line? $\mathrm{E}$, por fim, com que certeza poderemos imputar às mídias que propiciam outros modos de contato com a música, como é o exemplo do YouTube, do SoulSeek e do MySpace, a força para afetar criativamente a sociabilidade com base nos hábitos de escuta? A nossa questão cabal, no entanto, seria: como desarmar os hábitos cadenciados da memória e deixar que o mundo se renove a partir da arte, especialmente da escuta musical?

\section{Bergson e as imagens da memória: lembrança e reminiscência na escuta musical}

Não haverá muitos percursos promissores nos estudos sociais da música ligada à realidade da memória se não se fizer uma distinção aguda entre as diversas concepções do que vem a ser a memória. No entanto, é preciso desde já assumir que a memória precisa sofrer uma metamorfose conceitual, para que se torne produtiva a nossa especulação sobre o que ela tem a ver com a escuta e a sociabilidade musical. Pode-se começar dizendo que a habilidade da memória responde, no limite, por toda a nossa realidade sensível e é somente por elas que podemos dizer que existimos. Se a memória tem uma natureza, é preciso saber qual é o seu papel, bem como se processam as suas diversas operações e as diferentes temporalidades que elas criam.

No que diz respeito à prevalência histórica da concepção da memória como a faculdade pela qual despertamos as imagens de percepções passadas - tradição que se assenta nas idéias agostinianas - faz-se necessário citar brevemente a concepção de David Hume (2000). Muitos séculos depois de Santo Agostinho, ele afirmava que o trabalho da memória era o que nos faria conhecer uma continuidade e uma extensão nessa suposta sucessão de percepções. A memória seria assim o principal vetor na produção da identidade unívoca de um eu.

Já devemos cuidar de explicitar, neste ponto, uma séria recusa da noção defendida pelas correntes teóricas que adotam a figura de um 'sujeito cerebral', como é o caso particular da neurociência. Assentada na teoria da informação e na concepção computacional do cérebro, esta perspectiva acaba por reduzir a memória à esfera bioquímica do corpo. Ancorada numa visão espacializada da memória, a neurociência toma o cérebro e as suas células locais de armazenamento como mera arquivação do passado. Para o neurocientista, a memória se traduz por conexões de redes neurais sobre uma materialidade do cérebro, por meio de sinapses, por sua vez, moduláveis por hormônios. Ora, essa dedução de que a química fisiológico-molecular é a origem do psíquico humano, incorre num equívoco simplista, porque se assim fosse, haveria, como bem ilustrou Heidegger: "moléculas de despedida" (Heidegger apud Ferraz, 2007, 49).

Quem impulsionou uma reviravolta na concepção da memória foi o filósofo Henri Bergson, especialmente quando afirmou que o cérebro não servia para guardar ou arquivar lembranças, mas ao contrário, para suspendê-las, para mantê-las em sua condição virtual, evitando que elas nos açodem e que nos impeçam de agir no mundo. Ao aceitar que o cérebro também 
existe para afastar provisoriamente as lembranças, o pensamento de Bergson retira o esquecimento de uma negatividade e ressalta a sobrevivência do inconsciente como modo vital da existência. Mais do que selecionar o trabalho das imagens, o cérebro é responsável pela nossa capacidade de hesitar, de adiar, de suspender, de diferir, de fazer variar as promessas e ameaças que convocam as suas ações. É esta habilidade que nos tornaria capazes de participar na inovação do futuro.

Todas as coisas, para Bergson, existem num estado temporal que é misto e impuro. Todos os elementos já contêm algo daquilo que os precede e algo daquilo que os segue. Essa lógica da percepção - e das afecções, das imagens mentais - o leva a concluir que os momentos supostamente sucessivos do tempo não são jamais momentos reais das coisas, mas apenas momentos de nossa consciência. Esta é a principal operação da consciência na percepção: analisar o próprio movimento da memória que trabalha, contraindo uma multiplicidade de momentos para fazer deles uma síntese. É esta que unifica, numa 'imagem' simultânea, fluxos e durações inapercebidas, apenas rítmicas, vibratórias.

Bergson nos diz que o problema da gênese da percepção se deve, fundamentalmente, às sínteses mnemônicas. Memória e percepção vão juntas construindo todo o movimento à nossa volta. Aufere-se daî que a nossa percepção exige um enorme e contínuo esforço da memória. É ela que vai prolongar uma pluralidade de momentos uns nos outros. Cada percepção estende-se, ela própria, sobre uma certa espessura de duração, pelo fato de que a memória condensa aí uma multiplicidade enorme de durações. As antigas imagens, desse modo, costumam prolongar-se, gerando assim o movimento percebido. Isso significa que, aos dados imediatos captados pelos nossos sentidos, nós misturamos milhares de detalhes de nossa experiência passada. Ou seja, a nossa percepção do mundo é muito pouca coisa em comparação com tudo o que a nossa memória nela acrescenta.

Essa é a razão pela qual nós só percebemos, praticamente, o passado. Nós, por assim dizer, 'lembramos' o mundo. Essa idéia leva o autor a concluir que a percepção do presente é, por sua natureza, uma memória: não há, absolutamente, nenhuma percepção que já não esteja impregnada de lembranças, a ponto de não mais podermos sequer discernir o que é realmente percepção e o que é lembrança. Com isso, o filósofo inverte a concepção da correspondência entre percepção e memória, quando diz que a percepção nada mais é do que a estabilização sensorial de uma incalculável multiplicidade de contrações da memória.

Bergson distingue dois tipos básicos de memória: a 'memória-lembrança' e a 'memória-contração'. Ambas se processam, simultaneamente: a produção do passado, pela memória, e o imediatamente vivido. A primeira se diz da noção corrente da memória na qualidade de uma lembrança, de recordação, de rememoração ou de representação mental de uma sensação passada, que se realiza por imagens internas - as afecções. Concerne a nossa competência para realizarmos mentalmente imagens similares às que nos traz a percepção: imagens plásticas, formadas, além das abstrações ou das representações de cenas, narrativas, um símbolo, lapsos de um sonho, densidade atmosférica de um ambiente percorrido, um estado vivido etc. A memória-contração trata-se, diferentemente, de uma performance mnemônica que age antes da própria percepção ou da própria linguagem e por isso se aproxima daquela que mais importa à sensação na escuta musical. Esta modalidade mnemônica é aquela que chamamos aqui de reminiscência. Ao passo que estamos vendo coisas, ouvindo sons, sentindo a temperatura, gerando imagens mentais de toda ordem, muitos outros estremecimentos imperceptíveis e velocíssimos da memória estão em plena marcha.

Ainda há uma outra modalidade da memória, muitíssimo importante no processo perceptivo da escuta musical: a anamnese. Esta educação mnemônica trabalha religando momentos próximos. Ela é crucial para que, por exemplo, ao chegarmos ao fim de uma frase, lembremos do que ela se tratava ao início. Seria desesperador, por exemplo, esquecermos conexões entre elementos de uma idéia durante o processo do pensamento. $\mathrm{Na}$ escuta musical, especialmente, os exemplos mais simples dizem respeito ao reconhecimento de uma frase melódica, de uma célula rítmica, de um verso, de uma estrofe ou de um refrão, bem como de quais instrumentos estão em jogo nos últimos compassos, além dos magnetismos que as escalas ocidentais, por exemplo, as escalas em tons maiores e menores, exercem sobre a expectativa do ouvinte, antes de qualquer conteúdo que uma canção venha a suscitar. A anamnese funciona, de acordo com Herman Parret (1997), tomando a existência com um trabalho de inferência abdutiva. Por isso ela é o sentido do tempo rítmico-melódico. A anamnese fornece a temporalidade específica da memória rítmico-melódica ocidental, como uma experiência fusional que torna o tempo perceptível. Ela é o "temporizador que melodifica” (Parret, 1997, p. 72).

A anamnese na escuta musical aparece como um importante vetor da melodificação, porque ela produz uma mistura de tempos de várias durações. Na melodia são estabelecidas ligações no nível consciente, mas há muito mais ritmos subjacentes e inconscientes. A este respeito, Parret nos dirá que a anamnese, já sendo qualitativa, engendra uma temporalização muito específica, um processo paradoxal que combina a persistência das recordações com um apelo das antecipações. E essa mudança qualitativa é a mesma que advém da escuta de uma frase musical. Isso porque retemos cada uma das sensações para organizá-las com 
as outras e assim formar um grupo que evoca um ritmo reconhecido pelas 'soldas' da memória, porque na mais curta percepção de um som, trilhões de vibrações tomam lugar.

\section{Deleuze, as sínteses da memória e os tempos da música}

A fluidez fugidia da música, a sua evanescência material, parece ter motivado, desde muito tempo, práticas culturais que adotaram uma espécie de território mnemônico formalizador para instaurar uma objetividade na escuta. Na prática musical da Antigüidade grega se desenvolveu, entre os séculos $\mathrm{X}$ e IX a.C., o recurso do nomos: uma base rítmica estável passou a operar na escuta da música por padrões dinâmicos gerados por combinações entre tempos mais breves e mais longos. Mais tarde, também acolherse-iam células rítmicas modulando acentuações intensivas (tempos fortes e fracos) o que se efetivou por meio de formas reiterativas de durações perceptíveis e mais facilmente memorizáveis. Essa prática de adoção do nomos como uma plataforma temporal escandida de orquestração dos trabalhos da memória anamnésica passou a condicionar, no Ocidente, a escuta musical. Foram esses maquinismos semióticos, tais como a escansão, a rima, os versos entoados, os cadenciamentos, a estrofe e o refrão, por exemplo, que vieram a orientar a prática da música desde as remotas expressões líricas, dramatúrgicas e intrinsecamente musicais de compositores e ouvintes Antigos. Esses estados da percepção serão posteriormente traduzidos, por condicionamentos coletivos, em outros estados: em afecções (imagens interiorizadas), sentimentos, pathos, catarse etc.

Ainda hoje a escuta obedece a tudo aquilo que se coletiviza como memória musical: um sistema (modal, tonal, atonal), um contexto histórico, uma biografia, um movimento estilístico, uma técnica instrumental ou um certo dispositivo tecnológico, uma idéia anexa à composição etc. O chamado flashback na escuta musical é um exemplo da memória representada, de produção estereotipada de afecções e de sentimentos nostálgicos numa história biográfica de um ouvinte. Examinemos as lembranças de nossa história de vida ligada à escuta musical e poderemos constatar facilmente o quanto a memória trabalha na montagem de nossas experiências como ouvintes. E nos parece tão natural escutar objetivamente os sons, as notas, uma frase melódica, outra frase, uma combinação triunfal entre várias frases, arquitetadas por outras escansões, harmonizando-se e assim por diante. O correr de olhos sobre a capa de um disco, um texto na contracapa ativa incontáveis ritmos da memória que se maquinam para injetar nestes instantes diversas lembranças e reminiscências acavaladas. Mas tantas aptidões mnemônicas, sem a nossa liberdade de hesitar, de desativar certas propensões da lembrança, não garantem absolutamente nada a respeito do mundo das sensações inabarcáveis pela memória que ativam em nós o real poder da música.

Gilles Deleuze (1988) estima a existência de três sínteses de memória que operamos para fundar a nossa realidade vivida. Tal como Bergson, Deleuze assinala que a nossa experiência do tempo deriva de sínteses operadas por muitas habilidades da memória. As duas primeiras sínteses se distinguem por serem passivas (involuntárias) e as demais ativas (voluntárias). A primeira síntese, 'passiva', é gerada pelo hábito; a "segunda síntese, também 'passiva', nasce da reminiscência ou memória involuntária. A partir daí surgem a 'primeira síntese ativa', construída pela memória voluntária - a lembrança - e a 'segunda síntese ativa' - representação - que fundam a realidade semiótica e fenomenológica. Há, finalmente, uma 'terceira síntese'. Essa última nasce de nossa intervenção criativa nas 'imagens' e nos ritmos da memória.

O hábito, pensado como a 'primeira síntese passiva', é o modo pelo qual contraímos os instantes sucessivos, uns nos outros, no presente vivido. Essa retenção do hábito faz o estado dos instantes sucessivos se contraírem num estado percebido. A 'segunda síntese passiva do tempo' se realiza por uma memória ainda sem imagem. Esta reminiscência, involuntária, não qualifica nem reconhece, tampouco dramatiza a existência, mas, tal como a placa de retenção de contrações, faz com que o presente passe e dele advenham outros tempos. A "primeira síntese ativa" é gerada por nossa "memória voluntária" e já nos conduz a uma temporalidade derivada, quer dizer, representada. Note-se que a imagem do passado produzido por entrelaçamentos habituais de signos, de imagens formadas e de percepções.

A 'segunda síntese ativa', por sua vez, abarca toda a vida lingüística, semiósica, psicológica, moral, representacional, comunicativa, social etc. Esta síntese cadencia e acomoda os tempos esquivos à percepção a uma educação das performances da memória, para os fins de orientação de hábitos coletivos. As sínteses ativas, ao se erguerem sobre as sínteses passivas, tornam a se desdobrar em outras sínteses que vão se acavalando, numa impressão qualitativa, em instantes vividos, lembrados, homogeneizados em seus ritmos de imaginar, de sentir e de pensar. Por meio das sínteses que passam a contrair outras sínteses se dá uma passagem da sensação à imaginação espontânea e, destas, às faculdades ativas da representação, da rememoração, da recognição e do entendimento.

Isso implica que, na escuta, antes mesmo de reconhecer e apreciar certo fraseado melódico, esta ou aquela cadência de acordes, uma figura rítmica ou uma imagem anexa, sintetizam-se, maquinam-se, 
criativamente, não só tempos recognitivos da memória, da comunicação, do imaginário, mas também tempos que são insonoros, incorporais, inumanos. Essa sensação 'subpercebida' da escuta é o resultado de milhões de contrações silenciosas, reminiscências e lembranças operadas pelas nossas diversas sínteses do Tempo. São essas incontáveis sínteses, simultâneas, encavaladas, rítmicas, disjuntivas, que compõem a realidade paradoxal - virtual e sensível - da escuta musical. São, realmente, as notas de uma melodia que se tornam claramente apercebidas, mas as durações insonoras que 'contraímos' são uma outra face da música, as suas virtualidades, que nos afetam e criam sensações novas, muito antes do material, das formas e idéias musicais, e que também vão mais além delas.

\section{Notas conclusivas}

A mídia fonográfica, se pensada em suas facetas industrial e publicitária, se assenta seguramente num regime ultra-sofisticado de enunciação (o conjunto de discursos especializados e imagens ligados à música) e de simulação (as performances algorítmicas do desktop). Os especialistas do discurso sobre a música, por princípio profissionais, como os críticos ou os jornalistas, valem-se de um certo pacto tácito da memória social para afirmarem a obviedade do consenso sobre a realidade musical. Estes glosadores esquivam-se, contudo, de colocar questões incômodas aos preceitos intocáveis da persuasão propagandística. Evita-se levantar problemas acerca, por exemplo, de outras memórias que compõem a escuta, do desejo que move a criação, da sensação que escapa aos repertórios sentimentais, das virtualidades insonoras e, especialmente, do próprio caráter de convencimento inerente ao discurso midiático. Qualquer enunciado sobre música, por mais sofisticado e literário que seja, se embota diante da potência silente da escuta musical.

No que diz respeito ao marketing e à publicidade ligados à produção da música, estamos todos já bastante acostumados com os discursos anexos a buscarem predispor a nossa escuta para um consenso. Se a pauta de um artigo jornalístico, de uma resenha crítica ou de comentários de especialistas da música for, por exemplo, sobre uma composição de Tom Jobim e de Vinícius de Moraes, a tendência será um recorte de imagens de cenários da época, anedotas pitorescas (Rio de Janeiro, paisagens, vida noturna etc.), biografias, o conjunto da obra de Jobim, a bossa nova, os anos cinqüenta para a sociedade carioca, o contexto político-econômico, a modernidade na cultura brasileira, as reverberações entre outras artes contemporâneas etc. Memórias-lembranças sofrem enxertos de outras memórias, criando cadeias associativas. Não há nada de errado com esta prática de enunciar, de versar sobre as coisas da música, da arte, da sociedade, da cultura, mas também nada se diz da força da música dos dois compositores, porque essa, por princípio e por direito, é indizível, incaptável e irrecuperável pela rememoração.

É comum aos críticos da internet dizerem que quase tudo o que nos é apresentado no desktop, muito além dos usuais recursos discursivos, já vem prescrito, ao pormenor, nas maneiras de sua 'utilização'. A arquitetura informática, por esta via programática, reduz a freqüentação à rede a uma atividade mimética e obediente, o que acaba por pré-condicionar, por jogos simplistas de estímulos e respostas, os trabalhos da memória. A despeito de toda sofisticação na produção de hiper-realidades virtualmente simuladas, somos sutilmente conduzidos a fazer escolhas meramente binárias, bem como a dicotomizar o futuro por meio de decisões dualistas, de clique em clique, de link a link. Pensado por essa via crítica, quase tudo fica confinado a meros jogos de gratificações estereotipadas, excitadas por uma 'economia dos afetos', por uma prática sensacionalista, aquela que visa promover sensações previamente esperadas por quem as provoca.

O que se observa, em contrapartida, é a existência de certas iniciativas experimentais, criativas, nos modos de se freqüentar a internet em suas arquiteturas e em seus sítios-programas. Aqui adentramos em nosso principal exemplo: os 'sítios de redes sociais'. Na busca da criação de um programa de computador para dividir vídeos com os amigos, Chad Hurley e Steve Chen fundaram, em 2005, o YouTube. Este sítio-programa se tornou capaz de hospedar uma grande variedade de filmes, video-clipes e materiais caseiros. Ao exibir atualmente cerca de 100 milhões de arquivos por dia, o YouTube conquistou 46\% de participação de mercado dos vídeos on-line. O Yahoo, por exemplo, hoje enfrenta pressões para elevar seu investimento em serviços de redes sociais, uma vez que acompanha a dramática transferência de audiência para sítios como o YouTube, o MySpace e o Facebook.

Recentemente, o sítio foi comprado pelo Google, que almeja fazer dele um serviço de entretenimento pelo qual poderá integrar os seus diversos serviços e utilizar os seus links patrocinados (a sua principal fonte de renda). Para evitar questões que envolvam direitos autorais com representantes da indústria do entretenimento, o Google assinou contratos de distribuição de conteúdo com três grandes grupos de mídia: as gravadoras Universal Music Group, Sony BMG e com a rede de televisão norte-americana CBS. Por meio do acordo feito com a Sony BMG e com a Universal Music Group, essas oferecerão aos freqüentadores do YouTube o acesso a vídeos de seus arquivos. O acordo com a CBS oferecerá uma variedade de vídeos curtos da programação da rede, incluindo noticiários, esportes e entretenimento. 
O que nos surpreende, no entanto, é a vastidão inesgotável de registros audiovisuais do YouTube, no que tange especialmente à música. Há uma abundância vertiginosa de vídeo-clipes, concertos, trechos de musicais cinematográficos, fragmentos de documentários, entrevistas, seriados televisivos, vídeos amadores etc. muitos dos quais, desafortunadamente, jamais teremos tempo de assisti-los. Realimenta-se continuamente um acervo musical e imagético cuja espantosa mobilidade atordoa qualquer aporte teórico que se detenha para perscrutá-la. No entanto, é preciso explanar, mesmo que de modo muito breve, acerca das performances e das potencialidades do YouTube para a gama de experimentações que a realidade criativa da escuta pode assumir.

Demonstra-se, nos encontros com outros modos de criatividade expressos tecnologicamente, que estas iniciativas talvez tenham o poder de despir a escuta das imagens estereotipadas da cultura musical. As potencialidades de sítios que propiciam os hábitos de escuta on line multiplicando as conexões com a música propulsionam possibilidades de podermos ser arrancados, nem que seja por um lapso de tempo, de nossos territórios conhecidos. Abrem-se, desse modo, algumas brechas de indecidibilidade nas sensações, agindo como uma força diferenciante para a memória, indefinindo o seu destino - o futuro - por desarmes de lembranças estereotipadas e de hábitos condicionados. Sensações inesperadas, singulares, inabarcáveis pelos meros flash-backs musicais, poderão nascer ao se ultrapassarem, pelas micro-políticas da socialização de hábitos da escuta, as obediências da memória fixadas não só pelos dualismos do discurso midiático, mas também pelos algoritmos da simulação digitalizada. Mais do que um novo tipo de exercício da memória musical, a escuta que se liga aos sítios de redes sociais torna-se hábil no esquecimento de condicionamentos mnemônicos da cultura contemporânea da música.

\title{
Referências
}

BAUDRILLARD, Jean. The ecstasy of communication. in: FOSTER, Hal (Org.). The Anti-Aesthetic: essays on postmodern culture. The NY Press: New York, 2000.

BERGSON, Henri. Matéria e memória: ensaio sobre a relação do corpo com o espírito. São Paulo: Martins Fontes, 1999.

DELEUZE, Gilles. Diferença e repetição. Tradução de Luiz Orlandi e Roberto Machado. Rio de Janeiro: Graal, 1988.

FERRAZ, Sílvio. Livro das sonoridades: notas dispersas so- bre composição. Rio de Janeiro: Ed. 7 Letras, 2005.

FERRAZ, M. C. F. Bergson hoje: virtualidade, corpo, memória. In: LECERF, E.; BORBA, S.; KOHAN, W. (Orgs.). Imagens da imanência: escritos em memória de $\mathrm{H}$. Bergson. Belo Horizonte: Autêntica, 2007.

HUME, David. Tratado da natureza humana. Livro I, Parte IV, Seção VI. São Paulo: Ed. UNESP, 2000.

PARRET, Herman. Tempo, esse grande escultor. São Paulo: Ed. da Unicamp, 1997.

\section{The Rhythms of Memory: the Recollection and the Reminiscence on Online Musical Listening}

\begin{abstract}
This text aims at questioning methods of musical memory that trespass habits of frequency in the Internet. It proposes to question the intersections among mnemonic processes when listening on line and their potential for new ways of musical sociability. It is about knowing how a paradoxical experience such as listening - both as reality of sensations, as well as of socialized practices - can be differentiated by means of resources such as You Tube, SoulSeek or MySpace, among others. Taking for granted that musical experience results from the synthesis of multiple memories, it is believed that creative ways of approaching music by internet could boost singularities in mnemonic performances and in practices of socialization of listening as 'micro-policies'. This might produce some resistance to musical memory's orchestration of images by mass media culture.
\end{abstract}

Key words: musical listening; memory; sociability; internet.

Data de recebimento do artigo: 15-04-2008

Data de aprovação do artigo: 28-08-2008 